\title{
Multifactorial Analysis of Behavioural Responses of the Amphipod Corophium volutator to Temperature - Salinity Combinations
}

\author{
P. S. Meadows and A. A. Ruagh \\ Department of Zoology, University of Glasgow, Glasgow G12 8QQ, Scolland
}

\begin{abstract}
A multifactorial design for choice experiments is mathematically defined, and has been applied to study the combined effects of temperature and salinity on behavioural responses of Corophium volutator (Pallas). The behavioural responses used were preferences and activity in twochoice experıments. Twenty-six combinations of low (suboptimal, non-preferred), optimal, and high (supraoptimal, non-preferred) levels of each varlable were tested in 3 experimental series: (1) Constant salinity with temperature choice; (2) constant temperature with salinity cholce; (3) temperature and salinity choice. Optimal salinity was preferred to low or high salinities at each temperature. Optimal temperature was always preferred to low temperature at each salinity, but this was not true when the optimal temperature was offered with the high temperature. Temperature preferences overrode salınity preferences when both varied. Overall, temperature and salinity discrimination did not differ, but temperature discrimination decreased with increasing salinity while salınity discrimination was unaffected by temperature. Complex interactions occurred between temperature and salinity, in relation to their influence on activity. Temperature influenced activity when held constant at different levels, but not when offered as a choice. In general, total activity was lower in the preferred choice. Theoretical and practical aspects of the experimental design are discussed. Attention is drawn to the ecological significance of the results in relation to indirect and direct behavioural responses to environmental parameters, to possible behavioural and physiological differences between winter and summer populations, and to zoogeographical distributıons of species.
\end{abstract}

\section{INTRODUCTION}

The distribution of marine invertebrates in their natural habitats is influenced by a wide range of environmental variables. These variables will influence animal distribution at 3 levels. Under extreme conditions animals may actually be killed (Kanwisher, 1955); for example, many intertidal animals around British coasts were killed by the extreme cold winter of 1962/63 (Crisp, 1964). In less extreme conditions there are likely to be physiological changes which if prolonged may lead to death. For example food intake and growth rates can be reduced at suboptimal salinities and temperatures (Costlow et al., 1962; Manzi, 1970). However, the first response of any mobile species to environmental adversity is usually a behavioural one: individual animals strive to avoid actively unfavourable suboptimal conditions and to move into more optimal environments. This process is called habitat selection (Meadows and Campbell, 1972a, b).
Habitat selection under field conditions is likely to be determined by the combined effects of many variables rather than by the isolated effect of any single one. This complex problem can only be investigated properly under experimental conditions by multifactorial analyses of habitat preference. This means testing a large number of combinations of different levels of 2 or more variables in preference experiments. It appears that this approach has not been applied previously to habitat-choice behaviour of marine benthic invertebrates, although simpler designs have been used by Dorgelo (1975) for studying the responses of Gammarus species to salinity discontinuities at different temperatures, and by La Row (1970) for analysing the environmental factors controlling vertical migration of Chaoborus punctipennis Say larvae in fresh water.

The present paper presents for the first time a general multifactorial model which has been applied to assessing the influence of temperature-salinity combi- 
nations on the behaviour of the marine benthic amphipod Corophium volutator. Habitat choice and activity were recorded in 26 pairs of combinations of temperature and salinity by a new combinatorial experimental design. The design involves the assessment of animal behaviour in low and high non-preferred, and optimal preferred regimes. In general, one variable is offered as a choice and the other maintained constant at different levels, or both variables are offered as alternatives together.

\section{MATERLALS AND METHODS}

\section{Collection and Maintenance of Amphipods}

Mud containing Corophium volutator was obtained from a muddy beach at mid-tide level, at I.angbank. Clyde Estuary, Scotland (National Grid Ref. NS 390734 ). It was maintained at $10^{\circ} \mathrm{C}$ in the laboratory, in aerated sea water. Experiments were conducted on mature individuals (ca $5-7 \mathrm{~mm}$ carapace-telson length). The sex of animals was not noted. Animals were always used within $3 \mathrm{~d}$ of collection. Immediately before an experiment, the amphipods were removed from the sediment by sieving and were acclimated for 30 min in sea water at $20 \% \mathrm{~S}$ and $15^{\circ} \mathrm{C}$ - the preferred salinity and temperature of the species (McLusky, 1970; Meadows and Ruagh, 1981). Experiments were conducted within $1.5 \mathrm{~h}$ of high tide to reduce variability in activity (Morgan, 1965; Holmström and Morgan, 1979).

\section{Experimental Apparatus}

The choice apparatus used was a new one developed and tested by Meadows and Ruagh (1981) (Fig. 1). It

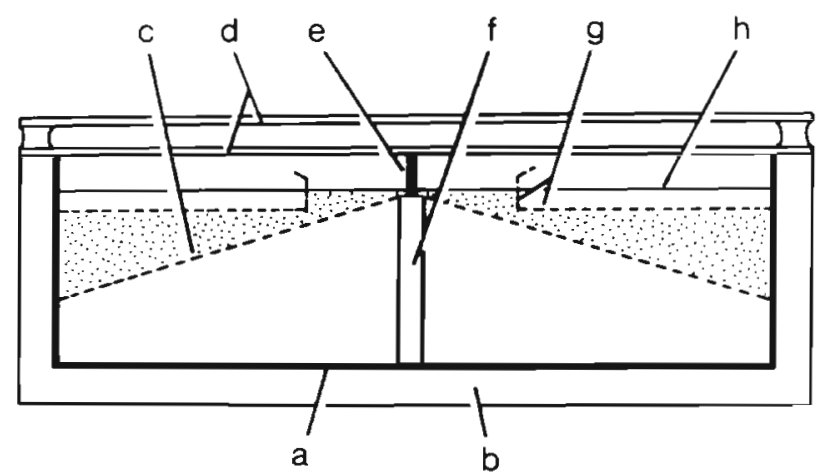

Fig. 1. Scale drawing of choice apparatus. a: clear plastic container; $b$ : expanded polystyrene insulation, thickness $1 \mathrm{~cm}$; : lower net; d: glass double glazing insulation; e: removable upper partition, not present during progress of experiment; $f$ : centre partition over which amphipods move; $\mathrm{g}$ : upper nets; $\mathrm{h}$ : water level. Amphipods are contained within the shaded area consisted of a clear plastic container of wall thickness $1.0 \mathrm{~mm}$, measuring $17.1 \mathrm{~cm}$ length, $11.3 \mathrm{~cm}$ breadth, and $5 \mathrm{~cm}$ height (Polystyrene container no. 141 . Stewart Plastics Ltd., Croydon, CR $94 \mathrm{HS}$, London). The container was divided into 2 chambers separated by a vertical partition over which the amphipods could move. Except over the centre partition, 2 nets in each chamber constrained the amphipods to a volume of liquid that did not mix with the liquid in the opposite side of the apparatus. The whole apparatus was carefully insulated and placed beneath a light source. Temperatures of solutions were set $1 \mathrm{C}^{\circ}$ above or $1 \mathrm{C}^{\circ}$ below the experimental temperature to allow for an observed maximum drift of $\mathrm{Ca} 2 \mathrm{C}^{\circ}$. Full details are given by Meadows and Ruagh (1981).

\section{Multifactorial Experimental Design}

The experimental design was developed from lattice theory (Birkhoff, 1967; Grätzer, 1978) and from the binomial distribution. Each parameter (e.g. temperature, ${ }^{\circ} \mathrm{C}$; salinity, \%o S) is considered to have a number of different levels (e.g. $5^{\circ}, 15^{\circ}, 25^{\circ} \mathrm{C} ; 5 \%$, $20 \%$, $35 \%$ S). There are

$$
\frac{x_{1} !}{\left(x_{1}-1\right) ! 1 !}=x_{1}
$$

ways of selecting one level from the $x_{i}$ levels in the $i$ th parameter. There are therefore

$$
x_{1} \times x_{2} \times \ldots \times x_{k}=\prod_{i=1}^{1=k} x_{1}
$$

ways of combining a single level selected from each of $k$ parameters. Hence there are

$$
-\frac{\left[\prod_{i=1}^{i=k} x_{1}\right] !}{\left[\left(\prod_{i=1}^{i=k} x_{1}\right)-r\right] ! r !}
$$

different ways of selecting $r$ different combinations from $k$ parameters. In other words, (2) represents the number of different ways of offering $r$ choices of $k$ parameters in a choice experiment. Fig. 2 shows (2) plotted against $r$ for selected values of $k$ and $\psi_{i}$. The curves of expression (2) in Fig. 2 are symmetrical about

$$
\left(\prod_{i=1}^{1=k} x_{i}\right) / 2
$$

Hence the number of possible combinations ( $y$-axis) is low for low and high numbers of choices ( $r$ ), but high 


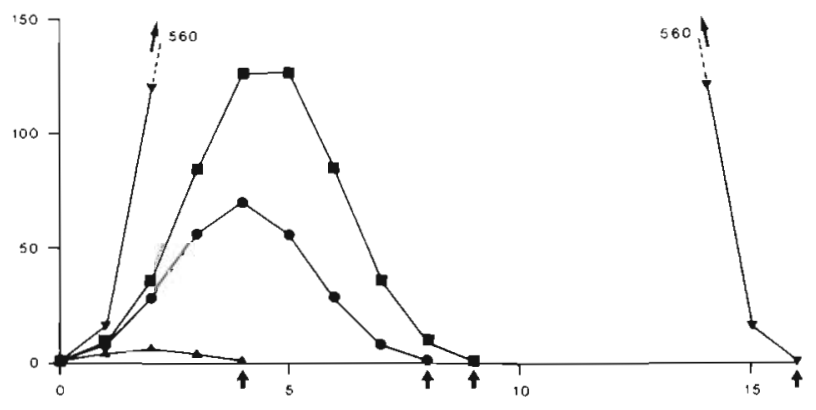

Fig. 2. Corophium volutator Examples of relationship between number of choices, $r$ (x-axis), and expression (2) (yaxis). Arrows on $x$-dxis represent $r_{\max }$ for each curve. $\mathbf{k}=2$, $\Pi x_{1}=3 \times 3 ; \bullet: k=3, \Pi x_{1}=2 \times 2 \times 2 ; \Delta \cdot k=2, \Pi x_{1}=$ $3 \times 3 ; \boldsymbol{\nabla}: k=2, \Pi x_{1}=4 \times 4$ and $k=4, \Pi x_{1}=2 \times 2 \times 2 \times 2$

for intermediate numbers of choices. The maximum number of choices in a choice experiment, $r_{\operatorname{lidx}}$, is

$$
\prod_{i-1}^{1-k} x_{1}
$$

(Fig. 2). In addition, when each parameter is offered at the same number of levels, $r_{\max }=x_{i}{ }^{h}$

In this paper, 2 parameters were tested, each at 3 different levels: temperature $\left(5^{\circ}, 15^{\circ}, 25^{\circ} \mathrm{C}\right)$, salinity ( $5 \%, 20 \%, 35 \%$ S). So $k=2$ and

$$
\prod_{i=1}^{1-2} x_{i}=3 \times 3=9
$$

Liquids were offered to amphipods in paired choices, so $r=2$. Substituting these values into (2) shows that there are 36 possible ways of choosing pairs of solutions from the 9 combinations of temperature and salinity for two-choice experiments. Twenty-six of these 36 possible pairs gave meaningful comparisons, and these were tested in 26 separate experiments

\section{Experimental Procedure}

The 3 salinities were chosen so that the middle salinity was the preferred optimum (20\% S) and the lower and upper salinities were non-preferred extremes (5\%, $35 \%$ S) (McLusky, 1970). The 3 temperatures were chosen in the same way $\left(15^{\circ} \mathrm{C}\right.$, preferred optimum; $5^{\circ}, 25^{\circ} \mathrm{C}$, non-preferred extremes) (Meadows and Ruagh, 1981). The resultant 9 temperature-salinity combinations used in the two-choice experiments are shown in Fig. 3.

The 26 choice experiments were divided into 3 series. Series 1 : in 9 of the 26, salinity remained constant and amphipods were offered a temperature choice, e.g. $\left(5^{\circ} \mathrm{C}, 5 \% \mathrm{~S}\right):\left(15^{\circ} \mathrm{C}, 5 \%\right.$ S $)$. Series 2 : in a further 9 , temperature remained constant and

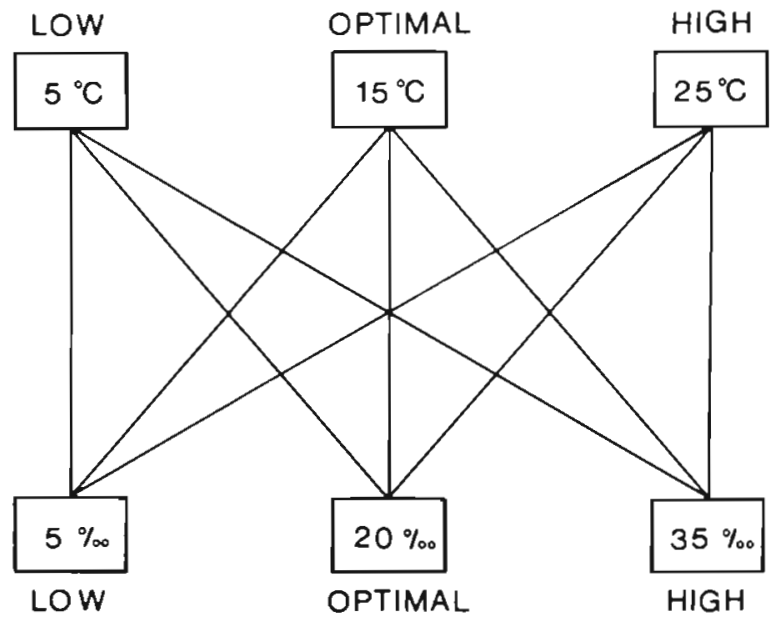

Fig. 3. The 9 temperature-salinity combinations used. Each line represents one combination

amphipods were offered a salinity choice, e.g. $\left(5^{\circ} \mathrm{C}\right.$, $5 \% \mathrm{~S}):\left(5^{\circ} \mathrm{C}, 20 \%\right.$ S). Series 3 : in 8 experiments amphipods were offered a choice of both temperature and salinity, e.g. $\left(5^{\circ} \mathrm{C}, 5 \% \mathrm{~S}\right):\left(15^{\circ} \mathrm{C}, 20 \% \mathrm{~S}\right)$. For example, in the upper left panel of Fig. 4 all experiments were conducted at $5 \% \mathrm{~S}$. Temperature in the 2 chambers of the apparatus was maintained, as shown, at $5^{\circ}$ and $15^{\circ} \mathrm{C}$, at $15^{\circ}$ and $25^{\circ} \mathrm{C}$, or at $5^{\circ}$ and $25^{\circ} \mathrm{C}$

Experiments were conducted in duplicate. In each duplicate experiment, 30 individuals were added to the apparatus, and the experiment was run for $30 \mathrm{~min}$ (Meadows and Ruagh, 1981). At the end of the experiment the number of amphipods in each side of the apparatus was recorded, and these preferences were analysed by $\chi^{2}$
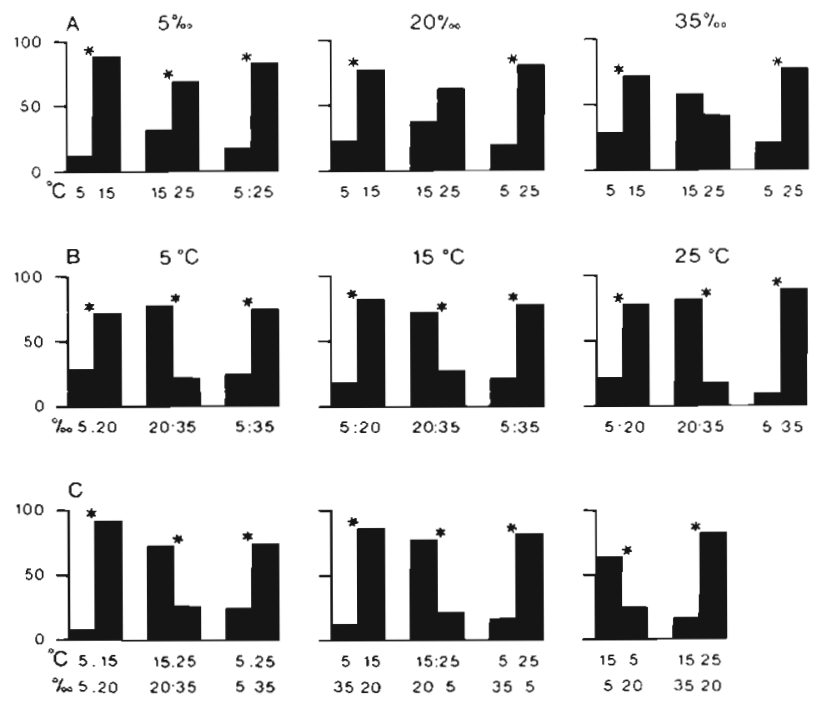

Fig. 4. Corophium volutator Temperature and salinity preferences at different temperature-salinity combinations. "Statistically significant preference by $\chi^{2}$. Duplicate experiments summed when results were found homogeneous by $\chi^{2} . y$-dxis percentage preference. A: Series $1 ; B$ : Series $2 ; C$ : Series 3 
Amphipod activity was recorded during each experiment using a Rustrak 4-channel event recorder and 4 micro-switches operated by finger pressure. Activity was classified into number of amphipods crossing the centre partition from each side to the other, and number of amphipods turning back from the centre partition from each side. These categories are subsequently referred to as crossings and turnings. Total activity is defined as crossings plus turnings. The crossings, turnings and total activity were expressed as activity/individual/min and then transformed to $\log _{10}$ for parametric statistical analysis (Sokal and Rohlf, 1969). Analysis was conducted on the activity data from the second $15 \mathrm{~min}$ of the experiments because preferences had become established by that time (Meadows and Ruagh, 1981).

Sea water of different salinities was prepared on the day previous to each experiment using 'Natura' sea salt with trace elements (Phillip Harris Biological Ltd. Oldmixon, Weston-Super-Mare, Somerset, England).

\section{RESULTS}

In the first series of experiments, temperature was varied and salinity maintained constant at 5,20 and $35 \%$ S (upper 3 panels, Fig. 4). Here, Corophium volutator significantly preferred the optimum temperature $\left(15^{\circ} \mathrm{C}\right)$ to the lower extreme temperature $\left(5^{\circ} \mathrm{C}\right)$ at all salinities. Amphipods did not distinguish between the optimum temperature and the higher extreme temperature $\left(25^{\circ} \mathrm{C}\right)$ except at the lowest salinity - when unexpectedly they preferred $25^{\circ}$ to $15^{\circ} \mathrm{C}$. When the 2 extreme temperatures were offered, amphipods always significantly preferred $25^{\circ}$ to $5^{\circ} \mathrm{C}$

In the second series of experiments, salinity was varied and temperature maintained constant at $5^{\circ}, 15^{\circ}$ and $25^{\circ} \mathrm{C}$ (middle 3 panels, Fig. 4). Here, amphipods significantly preferred the optimum salinity (20\%, S) to the lower $(5 \% \mathrm{~S})$ and higher $(35 \% \mathrm{~S})$ extreme salinities at all temperatures. When the 2 extreme salinities were offered, amphipods always significantly preferred $35 \%$ to $5 \% \mathrm{~S}$

The influence of salinity on temperature preferences in the first series, and of temperature on salinity preferences in the second series of experiments, were analysed statistically. Table 1 shows the influence of salinity on temperature discrimination in the first series. When the optimum temperature was offered with either of the 2 extremes, the absolute percentage difference between the number of amphipods in the preferred and non-preferred temperatures decreased with increasing salinity These decreases were highly significant in one instance $\left(25^{\circ} 15^{\circ} \mathrm{C}\right)$ and of borderline significance in the other $\left(5^{\circ}: 15^{\circ} \mathrm{C}\right)$. When the 2
Table 1. Corophium volutator. Influence of salinity on temperature discrimination. Analysis by $2 \times 3 x^{2}$ with $2 \mathrm{~d}$. $\mathrm{f}$ Absolute \% difference defined in text

\begin{tabular}{|c|c|c|c|c|c|}
\hline \multirow{2}{*}{$\begin{array}{c}\text { Tem- } \\
\text { perature } \\
\text { choice } \\
\left({ }^{\circ} \mathrm{C}\right)\end{array}$} & \multicolumn{3}{|c|}{$\begin{array}{l}\text { Absolule \% differ- } \\
\text { ence at different } \\
\text { constant salinities }\end{array}$} & \multicolumn{2}{|c|}{$\begin{array}{c}\text { Statistical } \\
\text { dnalysis }\end{array}$} \\
\hline & $5 \%$ & $20 \%$ & $35 \%$ & $x^{2}$ & $\mathrm{P}$ \\
\hline $5: 15$ & 77 & 5.3 & 43 & 5.269 & $0.10>P>0.05$ \\
\hline $25: 15$ & 37 & 23 & 17 & 9.441 & $0.01>\mathrm{P}>0.001$ \\
\hline $5: 25$ & 63 & 60 & 57 & 02082 & $0.90>P>0.80$ \\
\hline
\end{tabular}

extreme temperatures were offered, there was no significant change.

A similar statistical analysis on the second series of experiments showed no significant effect of temperature on salinity preference, when the optimum salinity was offered with either of the extreme salinities $(0.5>P>0.3)$. However, when the 2 extreme salinities were offered, temperature may have had an effect $\left(x^{2}=4.860,2\right.$ d.f., $\left.0.10>P>0.05\right)$.

The results of the first and second series were analysed further, to determine whether in general the degree of temperature discrimination was greater or less than the degree of salinity discrimination. For example, amphipods showing an $80 \%: 20 \%$ preference are assumed to be more discriminating than
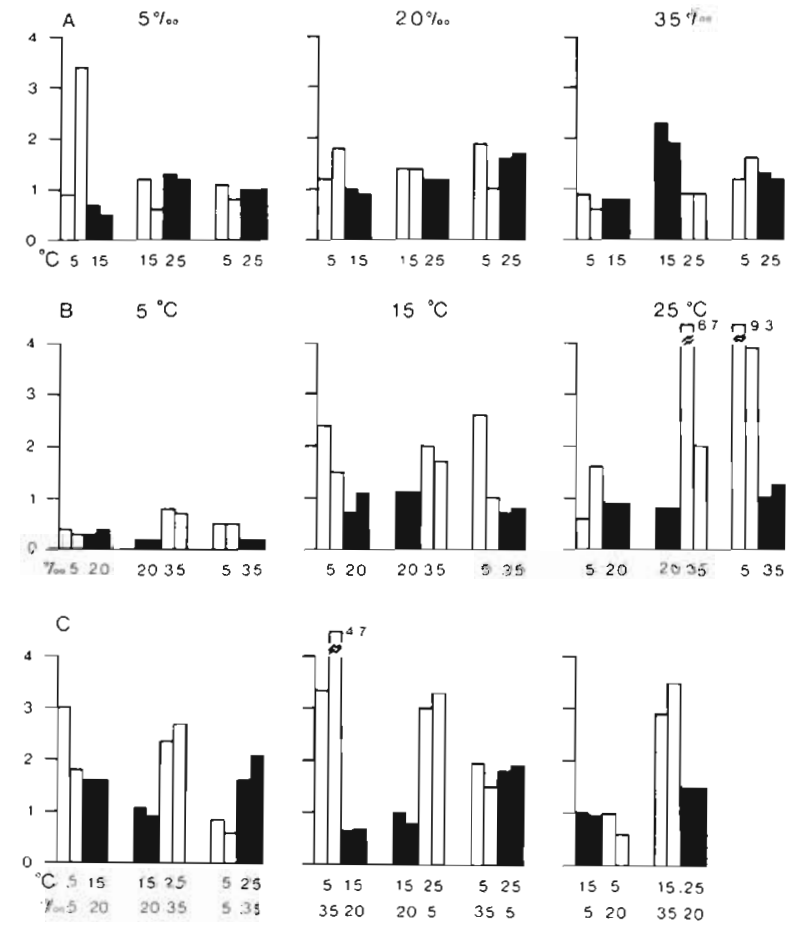

Figf. 5. Corophum volutator. Total activily d different temperature-salinity combinations. The y-axis scale represents total activity ind. 'mun' A: Series 1; B: Series 2; C: Series 3 Black columns: preferred choice; open columns: non-preferred choice 
amphipods showing a $60 \%: 40 \%$ preference. A Mann-Whitney U test was used to compare the absolute percentage differences between the numbers of amphipods in the preferred and non-preferred temperatures with the absolute percentage differences between the numbers of amphipods in the preferred and non-preferred salinities. There was no difference between temperature and salinity discrimination $\left(U_{1}\right.$ $=29, \mathrm{U}_{2}=51, \mathrm{n}_{1}=\mathrm{n}_{2}=9, \mathrm{P}>0.10$ ).

In the third series of experiments, both temperature and salinity were varied together. Amphipods always preferred the optimum temperature and salinity $\left(15^{\circ} \mathrm{C}\right.$. $20 \%$ S) to any other combination of temperature and salinity. As expected from the first 2 series, amphipods significantly preferred extreme high temperature and salinity to extreme low temperature and salinity. Temperature is more important than salinity in these choices, since $\left(25^{\circ} \mathrm{C}, 5 \% \mathrm{~S}\right)$ is significantly preferred to $\left(5^{\circ} \mathrm{C}, 35 \%, \mathrm{~S}\right)$ and $\left(15^{\circ} \mathrm{C}, 5 \% \mathrm{~S}\right)$ is significantly preferred to $\left(5^{\circ} \mathrm{C}, 20 \% \mathrm{~S}\right)$. Finally, amphipods significantly preferred $\left(25^{\circ} \mathrm{C}, 20 \% \mathrm{~S}\right)$ to $\left(15^{\circ} \mathrm{C}, 35 \%, \mathrm{~S}\right)$ which agrees with the first 2 experimental series.

Total activity in the 3 experimental series is shown in Fig. 5. There is a marked reduction in total activity at lower temperature in experimental Series 2. In addition, a comparison of Fig. 5 with Fig. 4 shows that activity was usually lower in the preferred choice. The total activity, crossings, and turnings were then analysed statistically after a $\log _{10}$ transformation.

Paired tests were applied to total activity, crossings, and turnings, and between non-preferred and preferred choices (Table 2). In general, total activity was significantly reduced in the preferred chamber $(1,2,3)$. However, when the data were analysed in detail, there were obvious differences between experimental Series

Table 2. Corophium volutator Analysis of differences in activity between non-preferred and preferred choices. + (non-preferred activity) > (preferred activity). - (non-preferred activity) < (preferred activity). Degrees of freedom (d. f.) $=17$, except in 1, 2, 3 (combined data from the 3 series) where d. $f .=51$ n. s.: statistically not significant

\begin{tabular}{|cccc|}
\hline $\begin{array}{c}\text { Data } \\
\text { analysed }\end{array}$ & $\begin{array}{c}\text { Experimental } \\
\text { series }\end{array}$ & $\begin{array}{c}\text { Paired } \\
t\end{array}$ & Probability \\
\hline \multirow{2}{*}{ Total activity } & $1,2,3$ & +3.969 & $\mathrm{P}<0.001$ \\
& 1 & +0.1327 & n. $\mathrm{s}$. \\
& 2 & +5.010 & $\mathrm{P}<0.001$ \\
& $1,2,3$ & +16.02 & $\mathrm{P}<0.001$ \\
Crossings & 1 & +7.063 & $\mathrm{P}<0.001$ \\
& 2 & +12.21 & $\mathrm{P}<0.001$ \\
& $1.2,3$ & -0.8492 & $\mathrm{n} . \mathrm{s}$. \\
Turnings & 1 & -3.691 & $0.01>\mathrm{P}>0.001$ \\
& 2 & +1.869 & $0.10>\mathrm{P}>0.05$ \\
\hline
\end{tabular}

1 and 2. In Series 1, when temperature was offered as a choice at constant salinities, there was no significant difference in total activity between the non-preferred and the preferred chamber In Series 2, when salinity was offered as a choice at constant temperatures, total activity was significantly lower in the preferred chamber The analyses in Series 3 (not given in Table 2) were significant. In the 3 series, crossings were always significantly higher from the non-preferred to the preferred chamber than vice versa (Table 2). Turnings were not significantly different in the preferred and non-preferred choices when the 3 series were considered together $(1,2,3)$. However, in Series 1 there were significantly more turnings in the preferred, and in Series 2 there were slightly more turnings in the non-preferred (Table 2).

Table 3. Corophium volutator. Six two-way analyses of variance on total activity in experimental Series 1 and 2. Mainfactor variance ratios only are given: main Factor $A=$ choice parameter; main Factor $B=$ constant parameter (salinity in experimental Series 1, temperature in experimental Series 2). Degrees of freedom: Factor $\mathrm{A}=1$ and 6 , Factor $\mathrm{B}=2$ and 6 . n. s.: statistically not significant

\begin{tabular}{|c|c|c|c|c|}
\hline \multicolumn{2}{|c|}{$\begin{array}{l}\text { Analysis } \\
\text { number }\end{array}$} & $\begin{array}{l}\text { Main } \\
\text { factors }\end{array}$ & $\begin{array}{c}\text { Variance } \\
\text { ratio }\end{array}$ & Probability \\
\hline \multicolumn{5}{|c|}{ Experimental Series 1} \\
\hline \multirow{2}{*}{1} & A & $5^{\circ} \mathrm{C} \cdot 15^{\circ} \mathrm{C}$ & 3.534 & n. 4. \\
\hline & B & salinity & 1.074 & n. s. \\
\hline \multirow{2}{*}{2} & A & $15^{\circ} \mathrm{C}: 25^{\circ} \mathrm{C}$ & 2.807 & $\mathrm{~ns}$. \\
\hline & B & salinity & 2.01 .6 & n. s. \\
\hline \multirow{2}{*}{3} & $A$ & $5^{\circ} \mathrm{C}: 25^{\circ} \mathrm{C}$ & 0.2568 & n. 5. \\
\hline & B & salinity & 3.582 & n.s. \\
\hline \multicolumn{5}{|c|}{ Experimental Series 2} \\
\hline \multirow{2}{*}{4} & A & $5 \%: 20 \%$ & 2.207 & n.s. \\
\hline & B & temperature & 17.16 & $0.005>P>0.001$ \\
\hline \multirow{2}{*}{5} & A & $20 \% \mathrm{~m}: 35 \mathrm{~m}$ & 28.72 & $0.005>P>0.001$ \\
\hline & B & temperature & 20.98 & $0.005>P>0.001$ \\
\hline \multirow{2}{*}{6} & A & $5 \%$ & 25.85 & $0.005>P>0.001$ \\
\hline & B & temperature & 32.64 & $P<0.001$ \\
\hline
\end{tabular}

A number of two-way analyses of variance were then applied to total activity, crossings and turnings in Series 1 and 2. A summary of the 6 analyses that were applied to the total activity data is given in Table 3. In each two-way analysis, main Factor $A$ represents the choice parameter and main Factor $B$ represents the constant parameter. For example, in Analysis 1 (Table 3) Factor A represents the $5{ }^{\circ} \mathrm{C}: 15^{\circ} \mathrm{C}$ choice of temperature, and Factor $\mathrm{B}$ represents the 3 constant salinities $\left(5,20,35 \%\right.$ S) at which the $5^{\circ} \mathrm{C}: 15^{\circ} \mathrm{C}$ choice was offered. In Series 1, none of the $\mathrm{A}$ or $\mathrm{B}$ factors was significant; in Series 2, all $A$ and $B$ factors were significant except one (Table 3). The $\mathrm{A} \times \mathrm{B}$ interaction 
factors were not significant, except the interaction in Analysis 2. These analyses show that temperature does not affect total activity when offered as a choice (Analyses $1,2,3$ ) but does affect total activity when it is held constant at 5,15 and $25^{\circ} \mathrm{C}$ (Analyses 4, 5, 6). The converse is true of salinity. Salinity usually affects total activity when offered as a choice (Analyses 5, 6), but does not affect total activity when it is held constant at 5,20 and $35 \% \mathrm{~S}$ (Analyses 1, 2, 3).

A similar set of 6 two-way analyses was applied to the crossings and to the turnings in experimental Series 1 and 2 . These analyses are not shown in the paper. The main factors were significant in 11 out of 12 analyses applied to the crossings and in 9 out of 12 analyses applied to the turnings. Hence both temperature and salinity influence crossings and turnings either when offered as a choice or when at their 3 constant levels.

\section{DISCUSSION}

The physiological responses of a wide range of marine invertebrates have been tested to combinations of salinity and temperature (Kinne, 1964; Alderdice, 1972). Behavioural responses to combinations of these variables, however, have received surprisingly little attention. Two predatory species of muricid gastropod, Eupleura caudata (Say) and Urosalpinx cinerea (Say), eat more spat of Crassostrea virginica Gmelin at higher temperature-salinity combinations (Manzi, 1970), and the sublittoral echinoid Lytechinus variegatus (Lamarck) rights its body most quickly at temperaturesalinity combinations similar to those in its natural environment (Lawrence, 1975). These investigations are not directly relevant to our results. Giere (1979) has described experimental devices which, in principle, may be used to test the behavioural responses of meiobenthic animals to temperature-salinity combinations; however, he tested no animals. Dorgelo (1975) tested the responses of female Chaetogammarus marinus (Leach) (= Marinogammarus marinus) and male Gammarus tigrinus Sexton to horizontal salinity discontinuities at 5,15 and $25^{\circ} \mathrm{C}$. These experiments are analagous to our second experimental series. As temperature increased, both species became more discriminating, and chose salinities that were closer to those of their normal habitat. The optimal preferred salinity of C. marinus is about $30^{\circ}, \mathrm{S}$ and of $\mathrm{G}$. tigrinus is about $0.5 \% \mathrm{~S}$ (Dorgelo, 1975), while that of Corophium volutator is about $20 \% \mathrm{~S}$ (McLusky, 1970). The optimal preferred salinity of $C$. volutator therefore lies between those of the 2 gammarid species. In spite of this, we found no statistically significant effect of temperature on salinity choice in $C$. volutator
(Fig $3 \mathrm{~B}$ ) This is surprising since $C$. volutator can occur in the same estuarine conditions as G. tigrinus (Burbanck, 1967, p. 571), and as C. marinus (Marine Biological Association, 1957). The above comparisons suggest that different estuarine species are likely to behave differently to salinity as the temperature varies.

The most efficient method of analysing the multiple effects and interactions of 2 or more environmental parameters on physiological or behavioural responses, is a factorial experimental design (Figs. 2, 3) (Snedecor and Cochran, 1967, Chapter 12; La Row, 1970; Alderdice, 1972; Hicks, 1973; Marsden, 1973; Lowthion, 1974). However, factorial choice experiments in which multiple combinations of parameters are offered to animals pose theoretical and practical problems, and have not been attempted previously.

Our theoretical analysis has been presented in the Material and Methods section. The practical problems are more difficult to surmount. The number of different possible combinations of choices increases rapidly as $k$ and

$$
\prod_{1-1}^{1-k} x_{1}
$$

increase $_{i}$ it also reaches a symmetric maximum for each curve

$$
\begin{gathered}
\text { (each combination of } \left.k \text { and } \prod_{i=1}^{1=k} x_{i}\right) \text { at } \\
\qquad\left(\prod_{i-1}^{i-k} x_{i}\right) / 2=r_{\operatorname{mid}} / 2
\end{gathered}
$$

(Fig. 2). We consider it impracticable to conduct choice experiments when the number of possible combinations of choices is greater than about 50 (Fig. 2, y-axis), especially since these choice experiments are usually conducted in duplicate or triplicate.

The bell-shape of each curve means that at its upper and lower extremes (on the $x$-axis) there are very few different possible combinations of choices ( $y$-axis). Experimentally, therefore, one should work in the lower or upper part of the curve. For example in this paper temperature and salinity were each tested at 3 levels (Fig. 3) so $k=2$ and

$$
\prod_{1=1}^{-2} x_{1}=3 \times 3=9
$$

At the lower and upper ends of the curve (Fig. 2, curve with squares), two-choice and seven-choice experiments ( $r=2$ or 7 ) each have 36 possible combinations of choices (Fig. 2, y-axis). By similar reasoning, using expression (2) again, the number is 84 , for three- 
and six-choice experiments, and 126 for four-and fivechoice experiments (Fig. 2). These latter numbers are near or at the central symmetric maximum of the curve, and are too high for experimental analysis. Two-choice rather than seven-choice experiments were conducted in our research because it is difficult to construct a choice apparatus which offers Corophium volutator equal access to seven choices of liquids; the apparatus design would have to be similar to that used by Meadows (1964) to study sediment-depth preferences.

The complex interactions reported in this paper may have important ecological implications. Salinity discrimination was unaffected by temperature. Therefore seasonal changos in water temperature, or temperature differences over the species' geographical range, are unlikely to affect salinity preferences and hence distribution in relation to salinity. However, temperature discrimination increased at lower salinities (Table 1), so amphipods should be more responsive to temperature changes towards the head of an estuary.

Our results are also relevant to the ecological and physiological tolerances of salinity and temperature of a number of marine species. Firstly, there is an established correlation that cold-water species can survive lower salinities in the field better than corresponding warm-water species with which their distribution overlaps. For example, there is a greater relative abundance of arctic species in the inner fjords of Norway and Alaska. This correlation suggests that it would be worthwhile investigating the temperature and salinity responses of Corophium volutator from the extremes of the species' geographical distribution.

Secondly, physiological responses to combinations of temperature and salinity can be affected by seasonal changes in water temperature. Hicks (1973) studied the combined effects of temperature and salinity on 2 species of New Zealand intertidal grapsid crab, Hemigrapsus edwardsi (Hilgendorf) and Hemigrapsus crenulatus (Milne-Edwards). This author firstly established the normal seasonal variation in temperature and salinity in Wellington Harbour, N. Z. He then picked 12 combinations of salinity and temperature that matched the natural range, and exposed winter and summer populations of the 2 species to these combinations. The winter and summer populations showed different responses for both species, although the differences were more obvious for $H$. crenulatus than for H. edwardsi (Hicks, 1973; his Figs. 3-6). Hicks also concluded that salinity was the dominant factor causing mortality, and that temperature-salinity interactions were more important in summer. In this context it would be interesting to compare the behaviour and physiology of summer and winter populations of Corophium volutator; however there are difficulties with this species since the size structure of
Corophium populations differs seasonally, and population densities are very low in winter.

Our results have a number of limitations. They only apply to Corophium volutator that are swimming. Nothing is known of the temperature-salinity responses of individuals when burrowed in sediment. However, under field conditions $C$. volutator does spend part of its time swimming (personal observations) with probable peaks of activity during the early ebb tide (Morgan, 1965). It is likely that at these times amphipods will respond to temperature-salinity combinations in the way described in this paper. In fact, all our experiments were deliberately conducted during the early ebb tide (within $1.5 \mathrm{~h}$ of high tide).

There is a second limitation. Our apparatus offered Corophium volutator discrete discontinuities of temperature and salinity. It is not known whether discontinuities of the order of magnitude tested in this paper occur under field conditions. However, in view of the mixing that occurs in many estuaries, gradients of different slope are probably more common than discrete discontinuity interfaces, although Kinne (1967, p. 526) implies that sharp vertical changes in temperature may sometimes develop.

Mobile estuarine animals, such as Corophium volutator, can avoid unfavourable temperatures and salinities directly or indirectly. These avoidance responses have been termed direct and indirect escape by Kinne (1967).

Direct avoidance involves animals reacting to an unfavourable salinity by moving away from that salinity into seawater of more favourable salinity. For example, in the second series of experiments, Corophium volutator avoids $5 \% \mathrm{~S}$ and prefers $20 \% \mathrm{~S}$ when offered a choice (Fig. 3 B).

In indirect avoidance, animals cannot avoid the unfavourable salinity because no favourable alternative is available. However, they may be able to ameliorate the adverse effects of the unfavourable salinity by moving to a more favourable temperature. There is some evidence for this type of response from our results, but it is not statistically significant. In the first series of experiments (Fig. $3 \mathrm{~A}$ ), the degree of preference for the optimal $15^{\circ} \mathrm{C}$ over both the nonpreferred $5{ }^{\circ} \mathrm{C}$ and the non-preferred $25^{\circ} \mathrm{C}$, is greater at a constant salinity of $5 \% \mathrm{~S}$ (low non-preferred salinity) than at a constant salinity of $20 \% \mathrm{~S}$ (optimal salinity)

Acknowledgements. A. A. Ruagh thanks El-Fateh University, Tripoli, Libya, for financial support. The authors thank Miss M. T Emerson and Mr. M. L. N. Murthy for secretarial assistance. 


\section{LITERATURE CITED}

Alderctice, D. F. (1972). Responses of marine poikilotherms to environmental factors acting in concert. In: Kinne, O. (ed.) Marine ecology, Vol. I, Environmental factors, Part 3. Wiley, London, pp. 1659-1722

Birkhoff, G. (1967). Lattice theory, 3rd ed, American Mathematical Society, Rhode Island

Burbanck, W. D. (1967). Evolutionary and ecological implications of the zoogeography, physiology, and morphology of Cyathura (Isopoda). In: Lauff, G. H. (ed.) Estuaries. Publs Am. Ass. Advmt Sci. 83, Washington, pp. 564-573

Costlow, J. D., Bookhout, C. G., Monroe, R. (1962). Salinitytemperature effects on the larval development of the crab Panopeus herbstii Milne-Edwards, reared in the laboratory. Physiol. Zool. 35: 79-93

Crisp, D. J. (ed.) (1964). The effects of the severe winter of 1962-1963 on marine life in Britain. J. Anim. Ecol. 33: $165-210$

Dorgelo, J. (1975). Comparative ecophysiology of gammarids (Crustacea: Amphipoda) from marine, brackish and freshwater habitats exposed to the influencc of salinity-temperature combinations. 2. Preference experiments. Verh. int. Verein. theor angew. Limnol 19: 3007-3013

Giere, O. (1979). Some apparatus for preference - experiments with meiofauna. J. exp. mar. Biol. Ecol. 41: 125-131.

Grätzer, G. (1978). General lattice theory, Birkhäuser, Stuttgart

Hicks, G. R. F. (1973). Combined effects of temperature and salinity on Hemigrapsus edwardsi (Hilgendorf) and $H$. crenulatus (Milne-Edwards) from Wellington Harbour, New Zealand. J. exp. mar Biol. Ecol. 13: 1-14

Holmström, W F., Morgan, E. (1979). Some properties of the tidal activity rhythm in the estuarine amphipod Corophium volutator. In: Naylor, E. (ed.) Cyclical phenomena in marine plants and animals. Pergamon Press, Oxford, pp. 355-356

Kanwisher, J. W (1955). Freezing in intertidal animals. Biol Bull. mar. biol. Lab., Woods Hole 109: 56-63

Kinne, O. (1964). The effects of temperature and salinity on marine and brackish water animals. II. Salinity and temperature-salinity combinations. Oceanogr. mar Biol. A Rev. 2: 281-339

Kinne, $O$. (1967). Physiology of estuarine organisms with special reference to salinity and temperature: general aspects. In: Lauff, G. H. (ed.) Estuaries. Publs Am. Ass Advmit Sci. 83, Washington, pp. 525-540

L.a Row, E. J. (1970). The effect of oxygen tension on the vertical migration of Chaoborus larvae. Limnol. Oceanogr $15: 357-362$

Lawrence, J. M. (1975). The effect of temperature-salinity combinations on the functional well-being of adult Lytechinus variegatus (Lamarck) (Echinodermata, Echinoideal. J. exp. mar Biol. Ecol. 18: 271-275

Lowthion, D. (1974). The combined effects of high salinity and temperature on the survival of young Limanda limanda. Mar. Biol. 25: 169-175

Manzi. J. J. (1970). Combined effects of salinity and temperature on the feeding, reproductive, and survival rates of Eupleura caudata (Say) and Urosalpinx cinerea (Say) (Prosobranchia: Muricidae). Biol. Bull. mar. biol. Lab., Woods Hole 138: 35-46

Marine Biological Association (1957). Plymouth marine fauna, 3rd ed., Marine Biological Association of the United Kingdom, Plymouth

Marsden, I. D. (1973). The influence of salinity and temperature on the survival and behaviour of the isopod Sphaeroma rugicauda from a salt marsh habitat. Mar. Biol. 21: 75-85

McLusky, D. S. (1970). Salinity preference in Corophium volutator. J. mar biol. Ass. U.K. 50: 747-752

Meadows, P. S. (1964). Experiments on substrate selection by Corophium volutator (Pallas): depth selection and population density. J. exp. Biol. 41, 677-687

Meadows, P. S., Campbell, J. I. (1972a). Habitat selection by aquatic invertebrates. Adv. mar. Biol. 10: 271-382

Meadows, P. S., Campbell, J. I. (1972b). Habitat selection and animal distribution in the sea: the evolution of a concept. Proc. R. Soc. Edinb. B 73: 145-157

Meadows, P. S., Ruagh, A. A. (1981). Temperature preferences and activity of Corophium volutator (Pallas) in a new choice apparatus. Sarsia 66: 67-72

Morgan, E. (1965). The activity of Corophium volutator (Pallas) and its possible relationship to changes in hydrostatic pressure associated with the tides. J. Anim. Ecol. 34: $731-746$

Snedecor, G. W., Cochran, W G. (1967). Statistical methods, 6th ed., Iowa State University Press, Iowa

Sokal, R. R., Rohlf, J. F. (1969). Biometry, the principles and practice of statistics in biological research, W. H. Freeman, San Francisco 